\title{
Stage IIB Rectal Neuroendocrine Tumor AJCC v8
}

National Cancer Institute

\section{Source}

National Cancer Institute. Stage IIB Rectal Neuroendocrine Tumor A/CC v8. NCI

Thesaurus. Code C135530.

Stage IIB includes: T3, N0, M0. T3: Tumor invading through the muscularis propria into subserosal tissue without penetration of overlying serosa. N0: No regional lymph node metastasis. M0: No distant metastasis. (AJCC 8th ed.) 